\title{
Neurological manifestations associated with COVID- 19: a review
}

\author{
Yasmim Berni Ferreira 1, Flávia Maria Ramos Freire 1, Victor Oliveira Araújo 1, Isadora Mônica Ponte \\ de Oliveira 1, Lara Maria de Oliveira Paiva Freitas 1, Júlio César Claudino dos Santos 1, 2, 3, *. \\ ${ }^{1}$ Faculdade de Medicina, Centro Universitário Christus, UNICHRISTUS. \\ 2 Universidade Federal de São Paulo, São Paulo, SP, Brasil. \\ ${ }^{3}$ Laboratório de Neurociências, Departamento de Neurologia e Neurocirurgia, Universidade Federal de São Paulo, \\ São Paulo, SP, Brasil.
}

*Corresponding author: Júlio César Claudino dos Santos. Departamento de Neurologia e Neurocirurgia. Universidade Federal de São Paulo. Rua Sena Madureira, 1500 - Vila Clementino. Zip Code: 04021-001 - São Paulo, SP, Brazil. Phone: +55 (19) 9 8450-6660. E-mail: cesar.claudino@unifesp.br.

Received on: Oct 3, 2021. Accepted on: Oct 3, 2021. Available online: Oct 7, 2021.

\begin{abstract}
The knowledge of the spinal cord irrigation is important for the therapeutic planning "COVID-19" is a potentially serious, highly transmissible infectious disease that was first identified in Wuhan, China in December 2019. Individuals infected with SARS-CoV-2 can evolve asymptomatically, with respiratory symptoms or with systemic manifestations affecting, for example, the nervous system. This review aims to discuss the neurological manifestations of SARS-CoV-2 infection, citing the prevalence of each. This study analyzed scientific articles published from 2010 to 2021 in the PubMed database. More than $35 \%$ of patients who contract the novel coronavirus develop neurological symptoms. SARS-CoV enters the brain mainly through the olfactory bulb and spreads rapidly via transneuronal route to other related areas such as cerebellum, insula, encephalon, vessels and nerves, and the brain parenchyma itself. This causes manifestations in the CNS (dizziness and ataxias), PNS (anosmia and ageusia), and the musculoskeletal system. Given existing knowledge of other coronaviruses and respiratory viruses, the wide range of CNS and PNS associations with COVID-19 is not surprising, and this is the focus of most current reports. Neurological complications, particularly encephalitis and stroke, can cause lifelong disability, requiring long-term care and substantial costs in the social and economic sphere.
\end{abstract}

Keywords: COVID-19; Neurology; Neuroscience.

\section{Introduction}

Severe acute respiratory syndrome coronavirus 2 (SARS-CoV-2), also called "COVID-19," is a potentially serious and highly transmissible infectious disease that was first identified in Wuhan, China in December 2019 [1-12]. The virus spread rapidly to 
all continents, leading the World Health Organization (WHO) to declare a pandemic in March 2020 [13]. Noteworthy in terms of the severity of the pandemic context, more than 170 million cases and 3.5 million deaths caused by the new coronavirus have been counted around the world by June 1,2021 [14].

Coronaviruses are positive-sense non-segmented RNA viruses belonging to the family Coronaviridae, also bound to angiotensin-converting enzyme 2 (ACE2) receptors in the nasal epithelium and lower respiratory tract, leading to respiratory symptoms [15]. The new coronavirus' nucleotide sequence has $89.1 \%$ similarity to the other Coronaviruses within the group, which makes it analogous to severe acute respiratory syndrome (SARS) [5, 11-12, 16-17]. This microorganism is classified as the genus Betacoronavirus, subgenus Sarbecovirus, and is the seventh member of the Coronaviridae family that can affect humans [6-7, 12, 16]. Among these viruses, NL63, HKU1, 229E and OC43 usually cause mild symptoms associated to a common cold, while the others are responsible for infectious diseases, including SARS in 2002 and 2003 (SARS-CoV), MERSin 2012 (MERS-CoV) and COVID-19 (SARS-CoV-2) [16].

$\mathrm{CoVs}$, such as SARS-CoV and Middle East Respiratory Syndrome CoV
(MERS-CoV), can adapt rapidly and cross the physiological barrier of species being capable of giving rise to epidemics or pandemics [1]. Although many aspects of COVID-19 are still unclear, it is known that the mechanisms of SARS-CoV and SARSCoV-2 to invade host cells involve the angiotensin-converting enzyme 2 (ACE2) receptor [7, 9-12, 18], and that SARS-CoV-2 is highly virulent. Therefore, the scientific evidence of SARS-CoV may aid studies of the clinical manifestations and pathophysiology of the new coronavirus due to the similar viral structure and receptor binding domain between the two viruses [1, 5, 9, 11, 16-17, 19-20].

COVID-19 virus can cross the blood-brain barrier through the ACE2 receptor, present on endothelial cells of the cerebral vasculature, acting as a cellular entry point for the virus [1, 8-9, 15 , 21]. SARS-CoV-2 most common symptoms are fever, cough, shortness of breath and fatigue, but some atypical symptoms such as loss of smell, taste and neurological changes have also been described [22]. In observational studies more than $35 \%$ of patients who contract the new coronavirus develop neurological symptoms [2], however, the mechanisms underlying this neurotropic behavior have not been well established. 
The neurotrophic mechanisms found previously in SARS-CoV and other viruses may serve as a reference for SARS-CoV-2 [16, 19-20]. There are two hypotheses to explain how COVID19 penetrates the Central Nervous System (CNS): 1) Hematogenous spread of SARS-CoV-2 through the systemic circulation into the cerebral circulation, where the slower flow is conducive for the virus to damage the capillary endothelium and gain access to the brain; 2) Dissemination through the cribriform plate and olfactory bulb via active axonal transport which, if similar to what occurs with $\mathrm{HCoV}-\mathrm{OC} 43$, the virus would spread first to the cortex, then to the hippocampus, and finally to the medulla [10, 12, 17, 19, 23-24].

The pathogenesis of COVID-19 is divided into three phases. In the first phase of infection, inflammation is present in the mucosa of the upper respiratory tract, and this is the period when the individual transmits the virus to others. During the second phase, SARS-CoV-2 invades and proliferates into the lungs, generating lung lesions, hypoxemia, and cardiovascular dysfunction. The last phase is characterized by the cytokine storm associated to vascular hyperpermeability, coagulopathies, and multisystem dysfunction [18].

The neurological manifestations described include headache, anosmia, dizziness, loss of consciousness, strokes, seizures, ataxia, acute disseminated encephalomyelitis, viral encephalitis, and "brain fog" [25-28]. These manifestations can be associated with a clinical scenario ranging from fever, non-productive cough and vomiting to asymptomatic [2, 8-9]. In addition, due to its affinity with ACE2, the same virus can affect other systems (such as the cardiovascular, digestive, and neurological), causing various clinical manifestations.

This literature review aims to discuss and contribute to a better understanding of the new coronavirus (SARS-CoV-2) as well as its neurological manifestations, given the limitation of previous studies involving COVID-19 and the nervous system and also the recent attention this association has received.

\section{Methodology}

This article presents a descriptive literature review based on the analysis of scientific articles published from 2010 to 2021 in the PubMed. The keywords used were: "COVID-19", "New Coronavirus (2019-nCoV)", "SARS", "SARS-CoV", "COVID-19 coronavirus", "SARS-CoV-2", "neurology", "neurological", "Neurological Manifestations" and "symptoms". The terminologies used in accordance with 
the Health Science Descriptors (DeCS) system.

The data search was conducted from July 2020 to June 2021 through online journals. Subsequently, materials were selected using the following inclusion criteria: thematic approach; publication date between 2010 and 2021; article available in full and/or abstract, and study in humans. We restricted our search to studies written in English. In order to ensure content saturation, the authors reviewed the references of included studies and relevant reviews on the topic to identify any missing publications. The authors participated in each phase of the review (Eligibility, Screening, and Inclusion), selecting articles that met the aforementioned selection criteria. The results of the studies are summarized in narrative form in each section of this review.

We present the process of selecting eligible data (Figure 1).

Figure 1. Flowchart of article selection with inclusion and exclusion criteria.

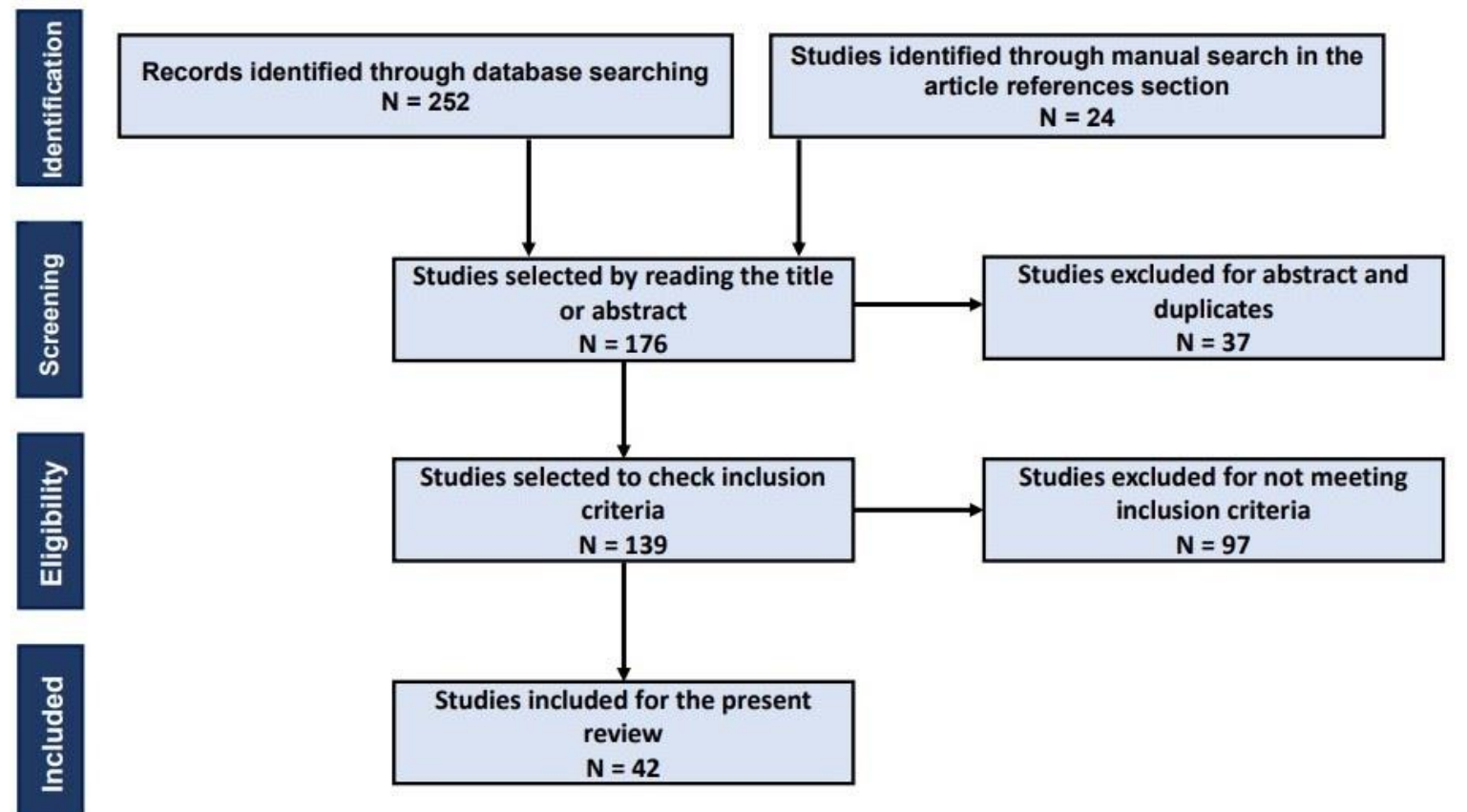

\section{Results (Review)}

SARS-CoV enters the brain mainly through the olfactory bulb and spreads rapidly via transneuronal route to other brain-related areas [16, 19-20]. Neurological manifestations are divided into 3 categories: central nervous system (CNS) manifestations (dizziness, headache, impaired consciousness, acute cerebrovascular disease, ataxia, and seizures), peripheral nervous system (PNS) manifestations (taste difficulty, smell difficulty, vision 
difficulty, and nerve pain), and musculoskeletal system manifestations [1].

\section{Olfactory Bulb}

Studies have observed that anosmia (loss of smell) has been manifested among some COVID-19 patients. This is due to the entry of SARS-CoV-2 into the CNS via the olfactory bulb, where viral lesions have the possibility to trigger inflammatory cascades through the microglia and proinflammatory cytokines, generating infection via the cribriform plate and olfactory bulb with subsequent transsynaptic dissemination of neural cells $[19,29]$. The viral interaction with the membrane, where there are bound ACE2 receptors expressed not only in nasal receptors and oral mucosa, but also in the nervous system, is relevant to this mechanism, since the route of the virus in the olfactory bulb is compatible with the observation of anosmia in the new coronavirus $[16,20]$.

Furthermore, studies have analyzed that the virus could undergo endocytosis in nerve terminals, being transported retrogradely and spread trans-synaptically to other brain regions [20]. Preliminary reports suggest that olfactory sensory neurons do not express ACE 2, thus preventing SARSCoV-2 from infecting these cells. However, cells of the olfactory epithelium do express ACE 2 and are vulnerable to infection by SARS-CoV-2. Consequently, damage to the olfactory epithelium, rather than neuronal lesions, appears to be the cause of anosmia [10]. Patients with olfactory loss may have alterations and high degeneration of the olfactory bulb, in addition to an olfactory cleft [30].

\section{Cerebellum, encephalon and anterior insula of the brain}

In addition, the study, "Neurological Manifestations of Patients Hospitalized with Coronavirus Disease 2019 in Wuhan, China" analyzed a total of 214 patients hospitalized with confirmed SARS-CoV-2 infection. Seventy-eight patients $(36.4 \%)$ had neurological symptoms: CNS (53 [24.8\%]), CNS (19 [8.9\%]) and skeletal muscle injury (23 [10.7\%]). Among patients with CNS manifestations, the most common symptoms were dizziness (36 [16.8\%]) and headache ([28.1\%]). Patients with PNS symptoms showed most commonly the appearance of dysgeusia (12 [5.6\%]) and hyposmia or anosmia (11 [5.1\%]) [1]. Although the sample size is limited, other studies with larger samples have found CNS symptoms such as headache and dizziness to be the most prevalent in patients with neurological manifestations.

The study "Understanding the neurotropic characteristics of SARS-CoV-2: from neurological manifestations of COVID- 
19 to potential neurotropic mechanisms" performed a systematic review of 554 patients with COVID-19, which showed that the mean prevalence of headache was $8 \% \quad(95 \% \quad$ CI $\quad 5.7-10.2 \%)$ and dizziness was $7-9.4 \%[5,19]$. These symptoms were also present in patients admitted to the Intensive Care Unit (ICU) $(\mathrm{N}=36)$ [16]. Furthermore, a metaanalysis that analyzed the incidence of neurological manifestations in 11,678 patients with COVID-19 showed similar results for headache and dizziness compared to the aforementioned study, but pointed out that individuals may also present impaired consciousness in $1.90 \%$ of cases (95 \% CI: $1.0 \%-2.79 \%$ ) [31].

An analysis of the disease course found that impaired smell or taste are early manifestations of COVID-19 and usually appear within the first 5 days of the disease [19]. It is also noteworthy that a cross-sectional study involving 287 individuals recovered from the new coronavirus found out that about $90 \%$ of patients with COVID-19 have symptoms after the acute phase of the disease [31], the most common neurological manifestations in this phase being "brain fog", a term meaning a set of nonspecific cognitive deficits, followed by headache, numbness, dysgeusia and anosmia [3233]. The severity during the acute phase and the presence of comorbidity in patients was related to the greater severity of symptoms in the post-acute phase [32]. Furthermore, the condition of immune-mediated inflammation and encephalopathy, common in COVID-19 patients, can generate cerebellar ataxia. Such manifestation however seems to be atypical in patients infected with SARSCoV-2[V2] as only one patient in the "Neurologic Manifestations of Hospitalized Patients with Coronavirus Disease 2019 in Wuhan, China" study showed cerebellar ataxia [1].

\section{Cerebral arteries and veins}

There is few present direct evidence for SARS-CoV-2 neurotropism, however, it is known that the viral structure and receptors of SARS-CoV-2 are similar to SARS-CoV [2]. Both viruses bind to the angiotensinconverting enzyme 2 (ACE2) receptor to access human cells $[1,5,9,11,16,17,19$ 20].

The review "The neurological manifestations of COVID-19: a review article" mentioned the hypothesis that angiotensin II receptor dysfunction due to SRA-COV-2 invasion may lead to impaired sodium and water regulation, resulting in arterial wall breakdown. Stroke associated with COVID-19 may be due to coagulation disorders and altered regulation of natural anticoagulant mechanisms which are caused by high levels of inflammatory mediators. It is observed that critically ill patients with the new $\mathrm{CoV}$ have a 
significant susceptibility for clot formation. In such cases, administration of anticoagulant medications appears to be associated with a better prognosis by reducing the risk of venous thromboembolism $[2,34]$.

The prevalence of neurological signs and symptoms is higher in patients with severe COVID-19 infection as the virus can affect the endothelium, favor a procoagulant state and involve the heart, which increases the patient's risk of developing a cerebral vascular accident (CVA) [35]. Stroke is a serious complication of SARS-CoV-2 infection, although the pathophysiology is not elucidated, evidence suggests the hypothesis that coagulopathy and endotheliopathy triggered by the cytokine storm are responsible for the incidence of associated cases [36]. It is emphasized that the relationship between this new virus and ACE2 is associated with the worsening also in patients with comorbidities because they have a weaker immune system [2].

Another study, the "Assessment of neurological manifestations in hospitalized patients with COVID-19" with sample size of 452 patient - 13 being SARSCOV-2 positive and 218 SARS-COV-2 negative (control group) - found data suggesting that comorbidities, such as diabetes and hypertension, increase ACE2 receptor expression in the brain and consequently neurotropism of the
SARS-CoV-2 virus [37]. However, a study in New York demonstrated that young patients (under the age of 50) developed large vessel strokes in the context of COVID-19, suggesting that all ages are vulnerable [6].

Researchers suggest that since patients died of COVID-19 exhibiting thickened pulmonary vascular walls, it must indicate pulmonary arterial hypertension (PAH) or at least a susceptibility for its development [37]. COVID-19 alterations in blood pressure control are another proposed mechanism to explain the increased risk of cerebral vascular complications. Normally, ACE2 signaling reduces blood pressure. Competitive blockade of ACE2 by SARS-CoV-2 virus reduces the expression of this enzyme leading to uncontrolled blood pressure and increased possibility of cerebrovascular events [21].

Given this, cardiac lesions in patients infected with the new coronavirus may be associated with increased morbidity and mortality. The tropism of SARS-CoV-2 and interaction with the RAAS system, via the ACE2 receptor, possibly increase the inflammation response and cardiac aggression in infected patients [38].

\section{Peripheral nerves}

Studies propose that the GuillainBarré syndrome, also known as acute demyelinating 
polyneuropathy (AIDP), although its exact etiology is still unknown, may develop after a gastrointestinal or respiratory infection [39]. This association can be explained through a molecular mimicry mechanism in which infecting viruses likely share epitopes similar to peripheral nerve components, which stimulates an autoreactive T- or B-cell response. The antibodies produced by the immune system to fight the virus cross-react by binding to gangliosides in the peripheral nervous system attracting inflammatory cells, such as macrophages, and subsequently causing neuronal dysfunction [6]. This disease is characterized by progressive and symmetrical limb weakness, absence of tendon reflexes on physical examination, sensory symptoms and facial weakness. According to case reports, 19 patients with Guillain-Barré syndrome associated with COVID-19 have been identified, most of them over the age of 60 [40].

Another research that analyzed 79 studies for qualitative synthesis and 63 studies for meta-analysis, showed that most cases of Guillain-Barré syndrome appeared after a time interval from primary COVID-19 infection. Therefore, it is likely that the pathogenesis is immune mediated postinfection [5].

\section{Brain parenchyma}

Another possible manifestation reported was the development of encephalitis associated with COVID-19 [40]. It is defined as an altered mental state lasting $\geq 24$ hours, together with one of the following criteria: a leukocyte count (WBC) in the cerebrospinal fluid $(\mathrm{CSF})<5 / \mathrm{mm}^{3}$; or the presence of a corresponding acute lesion on brain MRI [11], which may be caused by a local infection or by the body's immune defenses. In this same study, 9 adults aged between 24 and 78 years old were described with encephalitis associated with the new coronavirus, showing neurological features from the onset of respiratory symptoms until 17 days later [40]. There are several types of encephalopathy seen in patients with COVID-19, as hypertensive encephalopathy, for example, that may result from ACE2 reduction by SARS$\mathrm{CoV}-2$. This generates an increase in blood pressure, triggering a state of cerebral hyperperfusion and occasionally cerebral edema [11, 41]. Another category is hypoxic-ischemic encephalopathy, a syndrome resulting from a state of cerebral hypoperfusion following severe brain damage [11, 42].

Neurological symptoms such as headache, dizziness, loss of taste, and anosmia are the most prevalent in the studies cited in this review article. However, these signs will not always be 
the main neurological symptoms, and COVID-19 infection may present aggravated neurological manifestations such as stroke, especially in patients with comorbidities.

Therefore, researchers and healthcare professionals should not underestimate the clinical neurological repercussions associated with SARS$\mathrm{CoV}$ 2. The reason for that is it being a new disease and having still many aspects remaining unclear, especially in the neurological field.

\section{Conclusion}

Given existing knowledge of other coronaviruses and respiratory viruses, the wide range of associations of CNS and PNS with COVID-19 is not surprising and this is the focus of the most current reports. However, it is also likely that neurological disease will be seen increasingly in patients who are SARS-CoV-2-positive but with few or no features typical of COVID-19, based on knowledge of other epidemic viral infections and cases reported to date. Case control studies will be needed to help establish whether SARS-CoV-2 is causal or coincidental in such patients. Hypercoagulable states and cerebrovascular disease, which have been observed rarely for some acute viral infections, are an important neurological complication of COVID-19.
In general, the proportion of patients with neurological manifestations is small compared to the proportion of patients with respiratory disease. However, there is an expectation that $50-80 \%$ of the world's population may become infected before the development of herd immunity, suggesting that the total number of patients with neurological disease may become large. Neurological complications, particularly encephalitis and stroke, can cause lifelong disability, with associated long-term care needs and potentially large health, social, and economic costs. Health planners and policy makers need to be aware of the growing burden.

\section{References}

[1] Mao L, Jin H, Wang M, Hu Y, Chen S, He Q, Chang J, Hong C, Zhou Y, Wang D, Miao X, Li Y, Hu B. Neurologic Manifestations of Hospitalized Patients With Coronavirus Disease 2019 in Wuhan, China. JAMA Neurol. 2020 Jun 1;77(6):683-690. doi: 10.1001/ jamaneurol.2020.1127.

[2] Niazkar HR, Zibaee B, Nasimi A, Bahri N. The neurological manifestations of COVID-19: a review article. Neurol Sci. 2020 Jul;41(7):16671671. doi: 10.1007/s10072-020-04486-3. 
[3] Liotta EM, Batra A, Clark JR, Shlobin NA, Hoffman SC, Orban ZS, Koralnik IJ. Frequent neurologic manifestations and encephalopathy-associated morbidity in Covid-19 patients. Ann Clin Transl Neurol. 2020 Nov;7(11):2221-2230. doi: 10.1002/acn3.51210.

[4] Meppiel E, Peiffer-Smadja N, Maury A, Bekri I, Delorme C, Desestret V, Gorza L, Hautecloque-Raysz G, Landre S, Lannuzel A, Moulin S, Perrin P, Petitgas P, SellaI F, Wang A, Tattevin P, de Broucker $\mathrm{T}$; contributors to the NeuroCOVID registry. Neurologic manifestations associated with COVID19: a multicentre registry. Clin Microbiol Infect. 2021 Mar;27(3):458-466. doi: 10.1016/j.cmi.2020.11.005.

[5] Tsai ST, Lu MK, San S, Tsai CH. The Neurologic Manifestations of Coronavirus Disease 2019 Pandemic: A Systemic Review. Front Neurol. 2020 May 19;11:498. doi: 10.3389/fneur.2020.00498.

[6] Zubair AS, McAlpine LS, Gardin T, Farhadian S, Kuruvilla DE, Spudich S. Neuropathogenesis and Neurologic Manifestations of the Coronaviruses in the Age of Coronavirus Disease 2019: A Review. JAMA Neurol. 2020 Aug 1;77(8):1018-1027. doi: 10.1001/jamaneurol.2020.2065.
[7] Katal S, Balakrishnan S, Gholamrezanezhad A. Neuroimaging and neurologic findings in COVID-19 and other coronavirus infections: A systematic review in 116 patients. J Neuroradiol. 2021 Feb;48(1):43-50. doi: 10.1016/j.neurad.2020.06.007.

[8] Pinna P, Grewal P, Hall JP, Tavarez T, Dafer RM, Garg R, Osteraas ND, Pellack DR, Asthana A, Fegan K, Patel $\mathrm{V}$, Conners JJ, John S, Silva ID. Neurological manifestations and COVID-19: Experiences from a tertiary care center at the Frontline. J Neurol Sci. 2020 Aug 15;415:116969. doi: 10.1016/j.jns.2020.116969.

[9] Sardu C, Gambardella J, Morelli MB, Wang X, Marfella R, Santulli G. Hypertension, Thrombosis, Kidney Failure, and Diabetes: Is COVID-19 an Endothelial Disease? A Comprehensive Evaluation of Clinical and Basic Evidence. J Clin Med. 2020 May 11;9(5):1417. doi: 10.3390/jcm9051417.

[10] Harapan BN, Yoo HJ. Neurological symptoms, manifestations, and complications associated with severe acute respiratory syndrome coronavirus 2 (SARS-CoV-2) and coronavirus disease 19 (COVID-19). J Neurol. 2021 Sep;268(9):3059-3071. doi: 10.1007/s00415-021-10406-y. 
[11] Soltani Zangbar H, Gorji A, Ghadiri T. A Review on the Neurological Manifestations of COVID-19 Infection: a Mechanistic View. Mol Neurobiol. 2021 Feb;58(2):536-549. doi: 10.1007/s12035020-02149-0.

[12] Yavarpour-Bali H, GhasemiKasman M. Update on neurological manifestations of COVID-19. Life Sci. 2020 Sep 15;257:118063. doi: 10.1016/j.lfs.2020.118063.

[13] World Health Organization. WHO Director-General's opening remarks at the media briefing on COVID-19. 2020. Available from: https:// www.who.int/dg/speeches/detail/ whodirector-general-s-opening-remarks-atthe-media-briefing-on-covid-19--11march-2020.

[14] Johns Hopkins University. COVID19 Dashboard. The Center for Systems Science and Engineering (CSSE). Baltimore, Maryland: JHU, 2021 June 2 (real time). Available from: https://coronavirus.jhu.edu/ map.html.

[15] Paybast S, Gorji R, Mavandadi S. Guillain-Barré Syndrome as a Neurological Complication of Novel COVID-19 Infection: A Case Report and Review of the Literature. Neurologist. 2020 Jul;25(4):101-103. doi: 10.1097/NRL.0000000000000291.
[16] Zhou Z, Kang H, Li S, Zhao X. Understanding the neurotropic characteristics of SARS-CoV-2: from neurological manifestations of COVID19 to potential neurotropic mechanisms. J Neurol. 2020 Aug;267(8):2179-2184. doi: 10.1007/s00415-020-09929-7.

[17] Ibrahim W. Neurological manifestations in coronavirus disease 2019 (COVID-19) patients: a systematic review of literature. CNS Spectr. 2020 Oct 21:1-12. doi: $10.1017 / S 1092852920001935$.

[18] Garg RK. Spectrum of Neurological Manifestations in Covid-19: A Review. Neurol India. 2020 May-Jun;68(3):560572. doi: 10.4103/0028-3886.289000.

[19] Montalvan V, Lee J, Bueso T, De Toledo J, Rivas K. Neurological manifestations of COVID-19 and other coronavirus infections: A systematic review. Clin Neurol Neurosurg. 2020 Jul;194:105921. doi: 10.1016/j.clineuro.2020.105921.

[20] Iadecola C, Anrather J, Kamel H. Effects of COVID-19 on the Nervous System. Cell. 2020 Oct 1;183(1):16-27.e1. doi: 10.1016/j.cell.2020.08.028.

[21] Luigetti M, Iorio R, Bentivoglio AR, Tricoli L, Riso V, Marotta J, Piano C, Primiano G, Zileri Del Verme L, Lo 
Monaco MR, Calabresi P; GEMELLI AGAINST COVID-19

group.

Assessment of neurological manifestations in hospitalized patients with COVID-19. Eur J Neurol. 2020 Nov;27(11):2322-2328. doi: 10.1111/ene.14444.

[22] Adil MT, Rahman R, Whitelaw D, Jain V, Al-Taan O, Rashid F, Munasinghe A, Jambulingam P. SARSCoV-2 and the pandemic of COVID-19. Postgrad Med J. 2021 Feb;97(1144):110116. doi: 10.1136/postgradmedj-2020138386.

[23] Roy D, Ghosh R, Dubey S, Dubey MJ, Benito-León J, Kanti Ray B. Neurological and Neuropsychiatric Impacts of COVID-19 Pandemic. Can J Neurol Sci. 2021 Jan;48(1):9-24. doi: 10.1017/cjn.2020.173.

[24] Yachou Y, El Idrissi A, Belapasov V, Ait Benali S. Neuroinvasion, neurotropic, and neuroinflammatory events of SARS-CoV-2: understanding the neurological manifestations in COVID-19 patients. Neurol Sci. 2020 Oct;41(10):2657-2669. doi: 10.1007/s10072-020-04575-3.

[25] Stefano GB, Ptacek R, Patackova H, et al. Selective Neuronal Mitochondrial Targeting in SARS-CoV-2 Infection Affects Cognitive Processes to Induce
'Brain Fog' and Results in Behavioral Changes that Favor Viral Survival. Med Sci Monit. 2021 Jan 25; 27: e930886. doi: 10.12659/MSM.930886.

[26] Taylor AK, Kingstone T, Briggs TA, O'Donnell CA, Atherton H, Blane DN, Chew-Graham CA. 'Reluctant pioneer': A qualitative study of doctors' experiences as patients with long COVID. Health Expect. 2021 Jun;24(3):833-842. doi: 10.1111/hex.13223.

[27] Hellmuth J, Barnett TA, Asken BM, Kelly JD, Torres L, Stephens ML, Greenhouse B, Martin JN, Chow FC, Deeks SG, Greene M, Miller BL, Annan W, Henrich TJ, Peluso MJ. Persistent COVID-19-associated neurocognitive symptoms in non-hospitalized patients. J Neurovirol. 2021 Feb;27(1):191-195. doi: 10.1007/s13365-021-00954-4. Epub 2021 Feb 2. PMID: 33528824; PMCID: PMC7852463.

[28] Wang F, Kream RM, Stefano GB. Long-Term Respiratory and Neurological Sequelae of COVID-19. Med Sci Monit. 2020 Nov 1;26:e928996. doi: 10.12659/MSM.928996.

[29] Mahalaxmi I, Kaavya J, Mohana Devi S, Balachandar V. COVID-19 and olfactory dysfunction: A possible associative approach towards 
neurodegenerative diseases. J Cell Physiol. 2021 Feb;236(2):763-770. doi: 10.1002/jcp.29937.

[30] Kandemirli SG, Altundag A, Yildirim D, Tekcan Sanli DE, Saatci O. Olfactory Bulb MRI and Paranasal Sinus CT Findings in Persistent COVID-19 Anosmia. Acad Radiol. 2021 Jan;28(1):28-35. doi: 10.1016/j.acra.2020.10.006.

[31] Nazari S, Azari Jafari A, Mirmoeeni S, Sadeghian S, Heidari ME, Sadeghian S, Assarzadegan F, Puormand SM, Ebadi H, Fathi D, Dalvand S. Central nervous system manifestations in COVID-19 patients: A systematic review and meta-analysis. Brain Behav. 2021 May;11(5):e02025. doi: 10.1002/brb3.2025.

[32] Kamal M, Abo Omirah M, Hussein A, Saeed H. Assessment and characterisation of post-COVID-19 manifestations. Int J Clin Pract. 2021 Mar;75(3):e13746.

doi:

10.1111/ijcp.13746.

[32] Graham EL, Clark JR, Orban ZS, Lim PH, Szymanski AL, Taylor C, DiBiase RM, Jia DT, Balabanov R, Ho SU, Batra A, Liotta EM, Koralnik IJ. Persistent neurologic symptoms and cognitive dysfunction in nonhospitalized Covid-19 "long haulers".
Ann Clin Transl Neurol. 2021 May;8(5):1073-1085.

doi: 10.1002/acn3.51350.

[34] Wang H, Tang X, Fan H, Luo Y, Song $\mathrm{Y}, \mathrm{Xu} \mathrm{Y}$, Chen $\mathrm{Y}$. Potential mechanisms of hemorrhagic stroke in elderly COVID-19 patients. Aging (Albany NY). 2020 Jun 11;12(11):1002210034. doi: 10.18632/aging.103335.

[35] Michel P, Hirt L, Strambo D. "Covid-19 et AVC: associés ou non ?". Revue Médicale Suisse. 2021 Apr 28; 17 (736):816-821.

[36] Naval-Baudin P, Rodriguez I, Rubio-Maicas C, Pons-Escoda A, Viñas MMF, Nuñez A, Cardona P, Majos C, Cos M, Calvo N. COVID - 19 e acidente vascular cerebral isquêmico: achados clínicos e de neuroimagem. Journal of Neuroimaging. 2020 Sep 28;31(1);62-66. doi: 10.1111/jon.12790.

[37] Suzuki YJ, Nikolaienko SI, Shults NV, Gychka SG. COVID-19 patients may become predisposed to pulmonary arterial hypertension. Med Hypotheses. 2021 Feb;147:110483. doi: 10.1016/j.mehy.2021.110483.

[38] Azevedo RB, Botelho BG, Hollanda JVG, Ferreira LVL, Junqueira de Andrade LZ, Oei SSML, Mello TS, Muxfeldt ES. Covid-19 and the 
cardiovascular system: a comprehensive review. J Hum Hypertens. 2021 Jan;35(1):4-11. doi: 10.1038/s41371-0200387-4.

[39] Rodríguez $Y$, Rojas $M$, Pacheco $Y$, Acosta-Ampudia Y, Ramírez-Santana C, Monsalve DM, Gershwin ME, Anaya JM. Guillain-Barré syndrome, transverse myelitis and infectious diseases. Cell Mol Immunol. 2018 Jun;15(6):547-562. doi: 10.1038/cmi.2017.142.

[40] Ellul MA, Benjamin L, Singh B, Lant S, Michael BD, Easton A, Kneen R, Defres S, Sejvar J, Solomon $T$. Neurological associations of COVID-19. Lancet Neurol. 2020 Sep;19(9):767-783. doi: 10.1016/S1474-4422(20)30221-0.

[41] Lippi G, Wong J, Henry BM. Hypertension in patients with coronavirus disease 2019 (COVID-19): a pooled analysis. Pol Arch Intern Med. 2020 Apr 30;130(4):304-309. doi: 10.20452/pamw.15272.

[41] Vintila, I. Filip CR, Rociu C. Hypoxic-ischemic encephalopathy in adult. Acta Medica Transilvanica. 2010; 2(3):189-192.

Conflict of interest: The author declares no conflicts of interest.

Acknowledgements: None.

\section{Funding: None.}

How to cite this article: Ferreira $Y B$, Freire FMR, Araújo VO, Oliveira IMP, Freitas LMOP, Santos JCC. Neurological Manifestations Associated with COVID19: A Review. Brazilian Journal of Case Reports. 2021 Oct-Dec;01(4):31-44. 